prof. dr hab. inż. Jerzy Madej

dr hab. inz. Marian Medwid prof. nadzw.

dr Wtodzimierz Stawecki prof. nadzw.

Instytut Pojazdów Szynowych „TABOR”

\title{
Bezpieczny sprzęg międzynaczepowy dla modułu kolejowego uformowania naczep drogowych w kombinowanym ruchu kolejowo-drogowym
}

\begin{abstract}
Glówna cecha połaczenia międzynaczepowego na kolejowym szlaku transportowym jest niezawodność. Równie ważnq cechq wyróżniajaca takie połaczenie jest tatwość operacyjna w obrębie bimodalnego terminala. Dla spetnienia tych wymagań zostat zaprojektowany specjalny sprzęg międzynaczepowy; operacyjnie szybki, lekki do ręcznego udźwignięcia i niezawodny w pracy na szlaku. Niniejszy artykut stanowi prezentacje tego rozwiazania i jest wynikiem realizacji projektu rozwojowego NR R10-0065-10 „System transportu naczep drogowych na wózkach kolejowych w kombinowanym ruchu kolejowo-drogowym".
\end{abstract}

\section{MERYTORYCZNY ZAKRES ARTYKUŁU}

Od ponad dwudziestu lat są w Polsce prowadzone prace nad doskonaleniem systemu transportu naczep drogowych na wózkach kolejowych w kombinowanym ruchu kolejowo - drogowym. Jednym z elementów tych prac był (zakończony w roku 2013) projekt rozwojowy $\mathrm{Nr}$ 10-0065-10, którego charakterystycznym postulatem strukturalnym bylo tworzenie wielonaczepowych modułów transportowych. Wiadomo bowiem od wielu lat, że wyposażenie tyłu pojedynczej naczepy w kolejowe urządzenia pociagowo - zderzne, niezbędne dla transportowego uformowania kolejowego, znacznie zwiększa masę własną naczepy oraz nastręcza wiele trudności konstrukcyjnych. Zatem postanowiono wyposażać w kolejowe urządzenia pociagowo - zderzne jedynie wózki kolejowe podpierające przód naczep. Należało opracować sprzężenie tylnych części naczep $w$ obrębie modułu. Istotą modułowego systemu jest więc występowanie co najmniej dwóch naczep w kolejowo uformowanym module. Jednakże zależnie od ilości manewrowego miejsca na placu terminala może zachodzić konieczność rozłączania modułu. A musi to być operacja bezpieczna, nie wymagająca ani zbyt wielkiego wysiłku fizycznego, ani wchodzenia personelu pod podłogę.
Każda naczepa 1, w transportowym uformowaniu kolejowym, jest oparta w części przedniej na wózkach kolejowych krańcowych $\underline{\mathbf{2}}$, (wyposażonych w kolejowe urządzenia cięgłowo - zderzne) oraz - zależnie od miejsca naczepy w module - na wózkach międzynaczepowych $\underline{\mathbf{3}}$ (bez urządzeń zderznych). W części tylnej naczepa jest oparta na złożonych wózkach czteroosiowych $\underline{4}$. W każdym module transportowym o liczbie $\underline{\mathbf{n}}$ naczep, występują sprzęgi międzynaczepowe $\underline{\mathbf{5}}$ w liczbie $\underline{\mathbf{m}=\mathbf{n}-\mathbf{1}}$.

\section{BEZPIECZEŃSTWO FORMOWANIA MO- DULÓW}

W transporcie szynowym są szeroko znane i dość powszechnie stosowane samoczynne, zdalnie sterowane, sprzęgi międzywagonowe, szczególnie w zastosowaniach do transportu publicznego tramwajowego, kolejowego i metro. Odmiana samoczynna sprzęu nie wymaga ręcznych operacji i jest ergonomicznie preferowana zwłaszcza ze względów bezpieczeństwa pracy. Sprzęgi samoczynne wyróżniają się jednak znaczną masa, lecz umożliwiają manewrowo łatwe, częste i bezpieczne zdalnie sterowane łączenie/rozłączanie pasażerskich jednostek transportowych

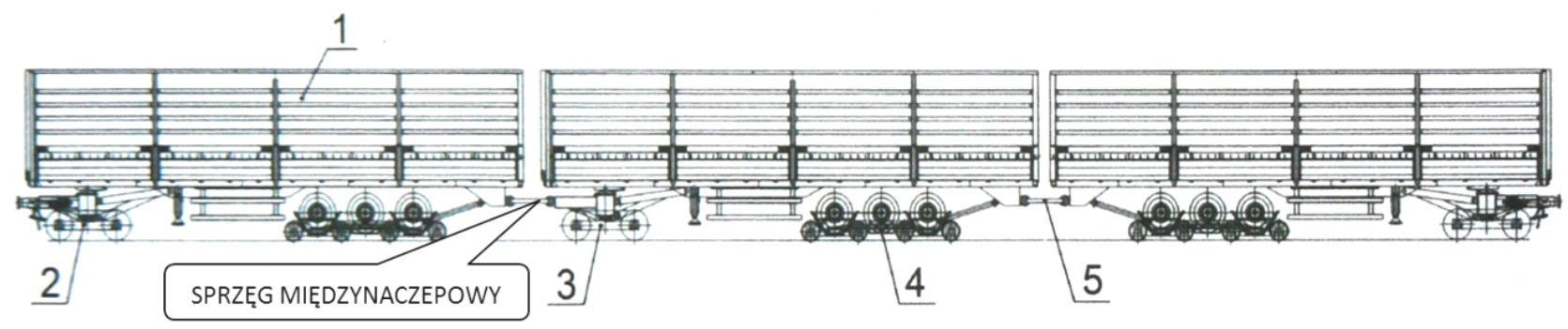

Rys. 1 - Moduł transportowy złożony z trzech naczep drogowych 
Klasyczna $w$ transporcie towarowym odmiana manualna sprzęgu (np. sprzęg śrubowy) wymaga ręcznych, niebezpiecznych operacji połączeniowych, dokonywanych przez pracownika w przestrzeni pomiędzy łączonymi lub rozłączanymi jednostkami transportowymi (wagonami).

Ze względu na przeznaczenie sprzęgu międzynaczepowego do towarowego ruchu naczep drogowych, należało odstapić od wymogu sterowania zdalnego i bezwzględnej samoczynności. Bezpieczny sprzęg międzynaczepowy dla modułowego systemu transportowego ma przede wszystkim zapewniać bezpieczeństwo jak też minimum operacji manualnych nie wymagających znacznego wysitku.

Przedmiotem niniejszej prezentacji jest kolejowy sprzęg międzynaczepowy, przeznaczony do łączenia jednostek transportowych w systemie kolejowego przewozu naczep drogowych. Ze względu na swą specyfikę system ten wymaga prostych operacji połączeniowych na każdej, formowanej do modułowego transportu kolejowego, naczepie drogowej. W tym przypadku nie ma możliwości całkowitego wyeliminowania manualnych operacji przygotowawczych do uformowania naczep w skład modułu, jak też operacji zabezpieczających przed przypadkowym rozłączeniem jednostek transportowych podczas ruchu pociagu na szlaku kolejowym.

Bogate doświadczenia pokazały, że sprzęgi naczep drogowych przeznaczonych do ruchu drogowo kolejowego powinny być wykonane najkorzystniej w odmianie mieszanej, manualno - zdalnej [2]. Ze względu na bezpieczeństwo formowania składu kolejowego manualne operacje łączenia (sprzegania) jednostek transportowych można dopuścić tylko w przestrzeni bocznej, bez konieczności wchodzenia pracownika pod naczepę lub pomiędzy naczepy stojące $\mathrm{w}$ torze kolejowym. Pewne przygotowawcze operacje manualne do sprzęgania jednostek transportowych można dopuścić nawet w przestrzeni tylnej, (za naczepa) i przedniej, (przed naczepa), gdy naczepa stoi nieruchomo w dostatecznym oddaleniu od innych nieruchomych naczep. Natomiast właściwe (ruchowe) sprzęgnięcie naczep $\mathrm{w}$ torze powinno się odbyć zdalnie, gdy nikt nie znajduje się pomiędzy naczepami. Po sprzęgnięciu i zatrzymaniu jednostek transportowych należy połączyć przewody hamulcowe oraz wykonać manualne operacje zabezpieczające skład przed rozprzęgnięciem podczas ruchu składu w torze.

\section{FAZY OPERACJI SPRZĘGANIA SĄSIED- NICH NACZEP MODULU}

Fazy operacji przedstawiono kolejno na rysunkach, przy czym rys. 3 przedstawia rysunek rurowego drąga cięgła sprzęgającego o niewielkiej masie (poniżej $30 \mathrm{~kg}$ ), zaś rys. 4 przedstawia rysunek zestawieniowy gniazda mechanizmu sprzęgu międzynaczepowego, zabudowanego w tylnej części nośnej ramy

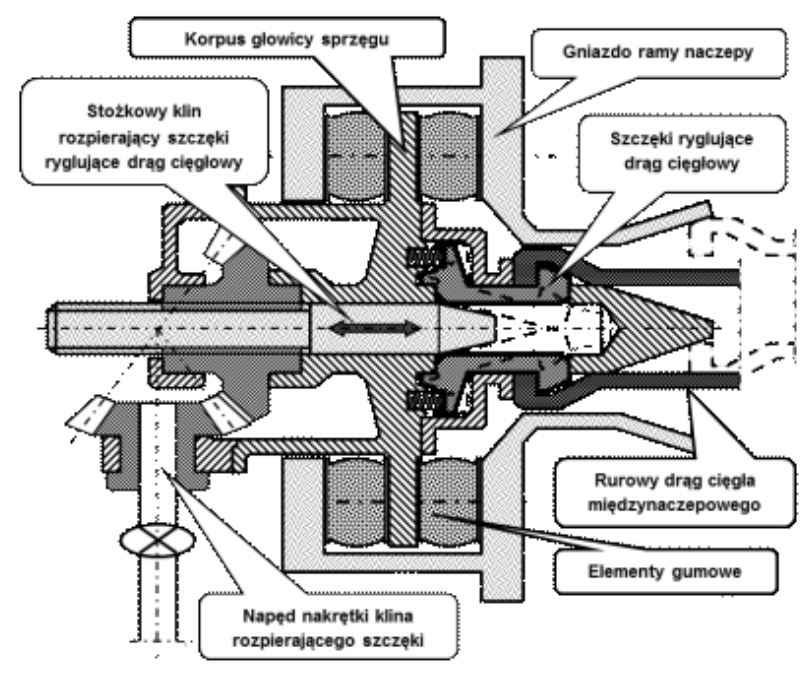

Rys.2. - Zestawieniowy rysunek gniazda międzynaczepowego mechanizmu sprzęgu $\mathrm{z}$ osadzonym w nim i zaryglowanym rurowym dragiem sprzęgającym

naczepy drogowej, przygotowanego do osadzenia draga $\underline{\mathbf{D}}$ w ześlizgowym kielichu Z.

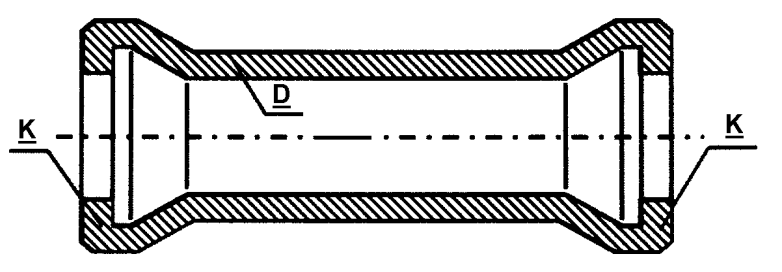

Rys. 3 - Drąg rurowy $\underline{\mathbf{D}}$ cięgła międzynaczepowego

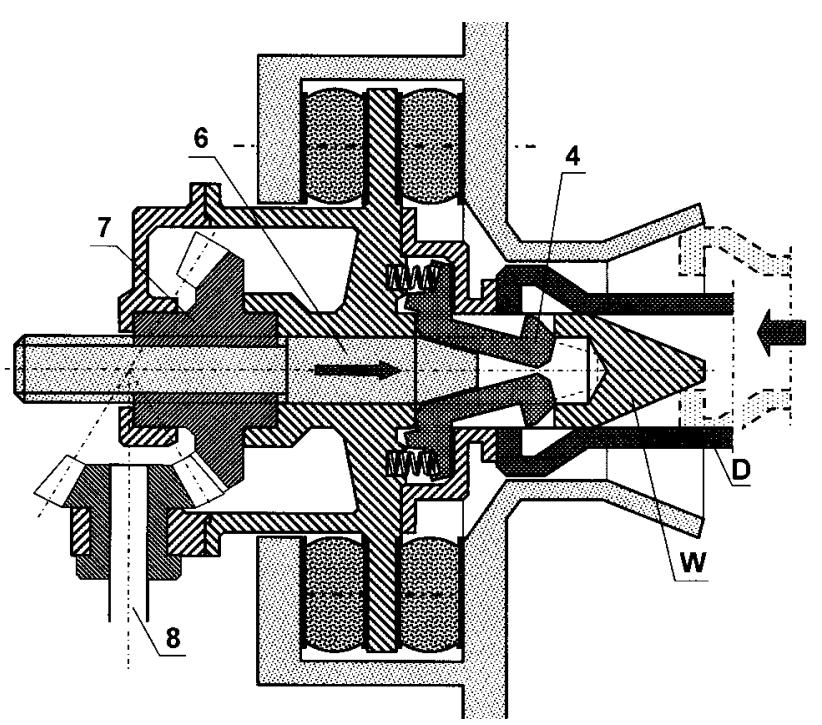

Rys.4 - Gniazdo mechanizmu sprzęgu międzynaczepowego z ręcznie nań nasadzonym rurowym drągiem sprzęającym $\underline{\mathbf{D}}$, gotowe do zaryglowania przez wsuwne wprowadzenie rozpierającego klina $\underline{6}$ pomiędzy szczęki ryglujące $\underline{4}$ za pomocą nakrętki $\underline{7}$ pokręcanej ręcznie poprzez wałek $\underline{\mathbf{8}}$

\section{Oznaczenia na rysunkach:}

$\underline{1}$ - korpus gniazda ramy naczepy wraz z kielichowym prowadnikiem $\underline{Z}$

$\underline{2}$ - korpus głowicy sprzęu wraz ze stożkowym prowadnikiem $\underline{W}$

$\underline{3}$ - poduszki gumowe zapewniajace wymagana sprężysta podatność ruchowa korpusu głowicy $\underline{2}$ w gnieździe ramy $\underline{1}$ 
$\underline{4}$ - szczęki ryglujace rurowy drag cięgła międzynaczepowego $\underline{D}$

$\underline{5}$ - sprężyny odryglowujace szczęki $\underline{4}$

$\underline{6}$ - klin rozpierajacy szczęki ryglujace $\underline{4}$

$\underline{7}$ - nakrętka zębata śrubowego przesuwu klina rozpierajacego $\underline{6}$

$\underline{8}$ - watek ręcznego pokrętta śrubowego przesuwajacego klin rozpierajacy 6 .

Manualne osadzenie drąga cięgła międzynaczepowego w gnieździe naczepy (przygotowywanej do uformowania modułu transportowego) jest dokonywane, gdy naczepa ta już spoczywa na wózkach kolejowych i pozostaje w należytym oddaleniu od następnej naczepy na wózkach. Następnie pracownik wychodzi poza obręb skrajni taboru i z zewnątrz pokręca wałek pokrętła śrubowego $\underline{\mathbf{8}}$ tak, że stożkowy klin rozpierający szczęki ryglujące $\underline{4}$ wprowadzi zęby tych szczęk w kołnierzowy wrąb rurowego draga $\underline{\mathbf{D}}$. W ten sposób naczepy obydwie naczepy zostają przygotowane do włączenia $\mathrm{w}$ jeden moduł bez konieczności wchodzenia pracownika w obręb skrajni taboru.

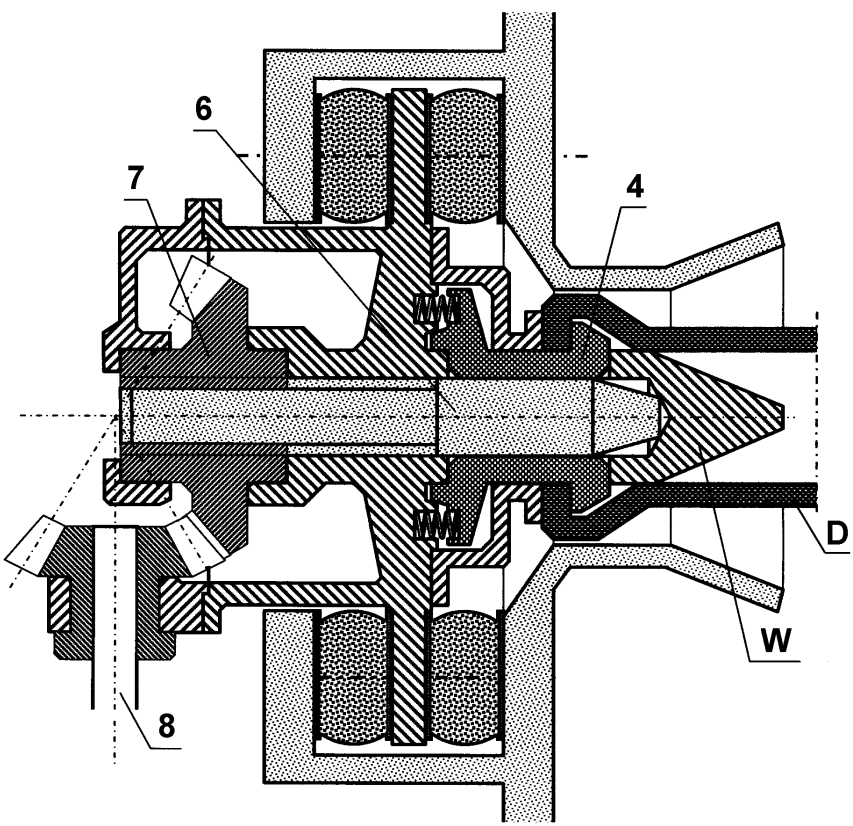

Rys.5 - Gniazdo mechanizmu sprzęu międzynaczepowego $\mathrm{z}$ ręcznie nań nasadzonym dragiem sprzęgającym $\underline{\mathbf{D}}$, zaryglowane przez rozpierający klin $\underline{\mathbf{6}}$, zabezpieczony przed obracaniem się, wsuwnie wprowadzony pomiędzy szczęki ryglujące $\underline{4}$ za pomocą nakrętki $\underline{7}$ pokręcanej ręcznie poprzez wałek $\underline{\mathbf{8}}$.

Osadzanie wolnego końca draga sprzęgającego D w gnieździe drugiej sprzęganej naczepy odbywa się już najazdowo, przy czym manualne czynności obsługi ograniczone są do zaryglowania draga rurowego $\mathrm{w}$ gnieździe drugiej naczepy za pomocą bocznego jej pokrętła $\underline{8}$. Tę końcową operację zilustrowano rysunkiem 6.

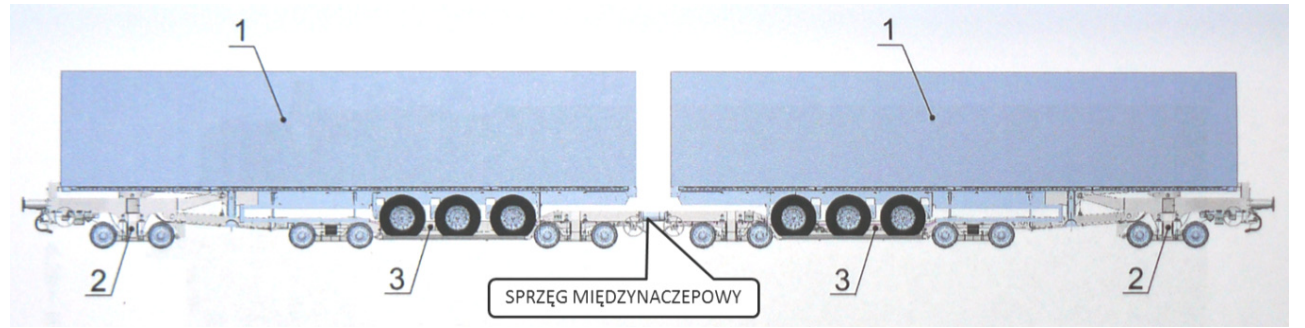

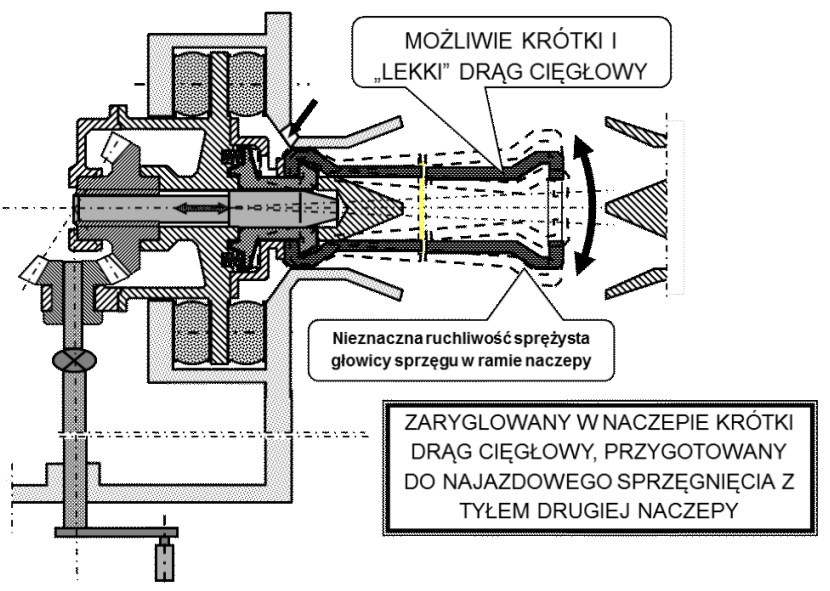

Rys. 6 - Ilustracja najazdowego sprzegania dwóch drogowych naczep tworzących kolejowy moduł transportowy

W zakończeniu należy podkreślić, że sprzęg międzynaczepowy, wyposażony w należycie wytrzymałe elementy, stanowiące integralne gniazdo ramy naczepy drogowej, zwiększa masę własną tej naczepy. Dlatego m. in. opracowano rozwojowy system modułowy (B), omówiony w podsumowaniu. $\mathrm{W}$ systemie rozwojowym (B) masa sprzęgu nie powiększa masy własnej naczepy drogowej.

\section{PODSUMOWANIE}

Budowa i działanie bezpiecznego sprzegu międzynaczepowego omówiono wyżej na przykładzie modułu trójnaczepowego (A), w którym wszystkie kolejowe składowe podłużne sił trakcyjnych są (według rysunku 1) przenoszone przez ramy naczep drogowych. W tym miejscu należy jednak podkreślić, że bezpieczny sprzęg międzynaczepowy może być równie dobrze zastosowany $\mathrm{w}$ takim konstrukcyjnym wariancie rozwojowym modułowego systemu transportowego naczep drogowych, w którym kolejowe składowe podłużne sił trakcyjnych sa przenoszone przez ramy części kolejowej systemu (B), jak pokazano na rysun$\mathrm{ku} 7$, zaś naczepy podlegają działaniu jedynie własnych sił bezwładności.

Bezpieczny sprzęg międzynaczepowy może mieć szerokie zastosowanie w kolejowym systemie transportu naczep drogowych. Rozwiązanie to zostało zgłoszone do opatentowania [1].

Rys. 7 - Bezpieczny sprzęg międzynaczepowy zastosowany w połączeniu części kolejowej modułu 


\section{Bibliografia}

[1] Zgtoszenie patentowe: Sprzeg międzynaczepowy.

[2] De Iorio, Antonio \& others: Fast connection system of decomposable structures of freight train for bi-modal transport; Journal of Rail and Rapid Transit 2012.

[3] Madej J., Medwid M.: Sprawozdanie merytoryczne z realizacji projektu rozwojowego NR 10-0065-10 pt: System transportu naczep drogowych na wózkach kolejowych w kombinowanym ruchu kolejowo-drogowym. Poznań 2013. Archiwum IPS „Tabor".

[4] Madej J., Medwid M., Cichy R., Jakuszko W., Nowaczyk T.: Modułowy system transportu naczep siodłowych na wózkach kolejowych w ruchu kombinowanym kolejowo-drogowym. XX Międzynarodowa Konferencja Naukowa „Pojazdy Szynowe 2012"-Poznań.
[5] Nowaczyk T.: Wybrane charakterystyki transportu intermodalnego (szynowo-drogowego). Praca magisterska NR TR-M/S-11/2009.

[6] Medwid M., Cichy R., Nowaczyk T.: Model strukturalny systemu transportu naczep drogowych na wózkach kolejowych w ruchu kombinowanym kolejowo-drogowym. Pojazdy Szynowe nr 2/2011. Wydawnictwo IPS ,,Tabor” Poznań.

[7] Nowaczyk T., Medwid M., Jakuszko W.: Technologia przeładunku poziomego na przykładzie modułowego systemu transportu kombinowanego. XIV Międzynarodowa Konferencja Nakowa „QSET 2013”-Niepołomice.

[8] Tomaszewski F., Medwid M., Nowaczyk T. Czerwiński J.: Cechy charakterystyczne modułowego systemu transportu naczep drogowych $w$ ruchu kolejowym $w$ odniesieniu do znanych systemów transportowych $w$ ruchu intermodalnych kolejowo-drogowych. Materiaty konferencyjne XI Konferencji Naukowej Pojazdy Szynowe. Wrocław 2014. 